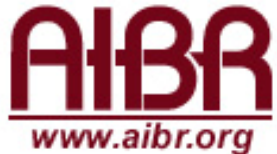

REVISTA DE ANTROPOLOGÍA IBEROAMERICANA

ESTIMADO LECTORIA:

GRACIAS POR DESCARGAR ESTE ARTÍCULO. EL TEXTO QUE ESTÁ A PUNTO DE CONSULTAR ES DE ACCESO LIBRE Y GRATUITO GRACIAS AL TRABAJO Y LA COLABORACIÓN DESINTERESADA DE UN AMPLIO COLECTIVO DE PROFESIONALES.

USTED PUEDE AYUDARNOS A INCREMENTAR LA CALIDAD Y A MANTENER LA LIBRE DIFUSIÓN DE LOS CONTENIDOS DE ESTA REVISTA A TRAVÉS DE SU AFILIACIÓN A LA ASOCIACIÓN AIBR:

http://www.aibr.org/antropologia/aibr/socios.php

La afiliación a AIBR tiene un coste mínimo al año, y le proporcionará las siguientes ventajas y privilegios:

1. Recibir en su domicilio la revista impresa, en Europa y América (tres números anuales), así como todas las novedades relativas al funcionamiento de la asociación

2. Recibir en su domicilio, a precio especial o de forma gratuita, cuantas publicaciones adicionales edite la asociación.

3. Derecho a voto en las asambleas de socios, así como a presentarse como candidato a la elección de su Junta Directiva.

4. Recibir el boletín de socios (tres números anuales), así como la información económica relativa a cuentas anuales de la asociación.

5. Beneficiarse de las reducciones de precio en congresos, cursos, libros y todos aquellos convenios a los que a nivel corporativo AIBR llegue con otras entidades. En este momento, existen los siguientes acuerdos:

o Reducción de un $20 \%$ en el precio de todos los libros publicados por la editorial MELUSINA.

o Reducción de un $20 \%$ en el precio de todos los libros publicados por la editorial SEPHA.

o Reducción de un 30\% en el precio de todos los libros publicados por la editorial GRAN VÍA.

o Derecho a cuota reducida en los congresos trianuales de la FAAEE (España) y a los bianuales de la Sociedad Española de Antropología Aplicada.

o Derecho a cuota reducida en los congresos la IUAES.

6. Promoción gratuita, tanto a través de la revista electrónica como de la revista impresa, de aquellas publicaciones de las que sea autor y que estén registradas con ISBN. La difusión se realiza entre más de 5.200 antropólogos suscritos a la revista.

7. Cuenta de correo electrónico ilimitada de la forma socio@aibr.org, para consultar a través de webmail o cualquier programa externo.

8. Espacio para web personal de la forma http://www.aibr.org/(directorio)/(nombre) y cuenta propia de ftp.

9. Acceso con clave a todos los documentos de la Intranet de socios de AIBR, incluida la consulta a artículos en proceso de evaluación de la revista AIBR.

10. Promoción gratuita a través de la revista (banner rotativo y reseña) de aquellos eventos, congresos, conferencias o cursos en los que usted forme parte del comité organizador.

11. Opción a formar parte como evaluador de los artículos recibidos por la revista.

IMPORTE DE LA CUOTA ANUAL: Hasta diciembre de 2008, la cuota única anual es de 32 (euros). Su validez es de un año a partir del pago de la cuota. Por favor, revise la actualización de cuotas en nuestra web.

PARA HACERSE SOCIO DE AIBR, POR FAVOR, CONSULTE LA SIGUIENTE DIRECCIÓN:

http://www.aibr.org/antropologia/aibr/socios.php 


\title{
e? DIAGNÓSTICO SOCIO-AMBIENTAL PARA UN www.aibr.org DESARROLLO SUSTENTABLE DE LA PUNA MERIDIONAL ARGENTINA, LOCALIDAD DE ANTOFAGASTA DE LA SIERRA, CATAMARCA
}

\author{
Liliana M. Manzi
}

Consejo Nacional de Investigaciones Científicas y Tecnológicas, CONICETIMHICIHU-DIPA.

Recibido: 10 de enero de 2007 Aceptado: 21 de diciembre de 2007

\section{Resumen}

Se presenta un diagnóstico socio-ambiental realizado en la comunidad de Antofagasta de la Sierra, Provincia de Catamarca, Argentina, siendo tomados en consideración las unidades sociales de producción, los rebaños, las pasturas disponibles y los patrones de uso y tenencia de la tierra.

Se pretende identificar y evaluar la incidencia del actual uso del espacio sobre el medio natural y discutir las iniciativas oficiales de desarrollo económico para este sector de la Puna argentina.

\section{Palabras Clave}

Economías de autosubsistencia, pastores, manejo de recursos, desarrollo sustentable

SOCIAL AND ENVIRONMENTAL DIAGNOSIS FOR A SUSTAINABLE DEVELOPMENT IN THE ARGENTINIAN MERIDIONAL PUNA, IN ANTOFAGASTA DE LA SIERRA, CATAMARCA

\begin{abstract}
This paper analyzes the social and environmental space used by the Antofagasta de la Sierra community in the province of Catamarca, Argentina. It considers the social units of production, animal populations, available pastures and the patterns of use and possession of the land. It aims to identify and evaluate patterns regarding the use of space and the natural environment and discusses the official incentives for economic development for this sector of the Meridional Puna, Argentina.
\end{abstract}

\section{Keyboards}

autosubsistence economies, pastoralism, resources management, sustainable development 


\section{Agradecimientos}

Quiero manifestar mi agradecimiento a la Comunidad de Antofagasta de la Sierra, especialmente a don Vicente Morales y a doña Angela Vázquez por ayudarme a comprender algunos aspectos de la vida diaria en ese sector de la Puna.

Al Señor Intendente, Constructor Eduardo Rodríguez, y a su Secretario, Técnico Agrónomo Lucas Soriano, por realizar los traslados al campo en el transcurso de las investigaciones realizadas en el terreno y por responder a muchas preguntas.

\section{Introducción}

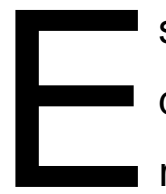

sta propuesta tiene como finalidad realizar un diagnóstico socio-ambiental de las actividades productivas desarrolladas por los pastores puneños, residente en la localidad de Antofagasta de la Sierra, Provincia de Catamarca, Argentina.

La economía antofagasteña se sustenta básicamente en el pastoreo de rebaños mixtos de cabras (Capra hircus), ovejas (Ovis aries) y llamas (Lama glama) dentro de un arraigado esquema andino de apropiación del medioambiente y de organización social, directamente orientado a garantizar la autosubsistencia de las familias. Motivo por el cual, dentro de las unidades domésticas o familiares es producida la mayor parte de los elementos de consumo, a la vez que se generan escasos excedentes.

La vinculación entre los productores antofagasteños con las economías regionales es poco intensa, siendo posible a través del accionar de comerciantes establecidos en la Villa de Antofagasta y de comerciantes trashumantes que recorren los ambientes de puna (por encima de los $3400 \mathrm{~m}$. snm), de valles y quebradas (ca. 2500 m. snm) y de valle (ca. 700 m. snm).

La situación observada es considerada en relación con una propuesta de desarrollo textil, a partir de la producción de fibra animal, para la Puna catamarqueña e impulsada por el gobierno provincial con sede en la ciudad de San Fernando del Valle de Catamarca, distante unos $650 \mathrm{~km}$. Desde allí se planificó un eventual desarrollo económico de la Puna; región que consideran inmersa en un alarmante atraso económico. Esto hizo que se proyectaran propuestas económicas contando con la participación de entes oficiales, el municipio y de empresarios no residentes en el área. 


\section{El área de estudio}

El Departamento de Antofagasta de la Sierra comprende el sector meridional de la Puna argentina, también denominado puna sur (Bolsi, 1968) o salada (Núñez y Santero, 1988) (FIGURA 1). Enmarcado en el ángulo noroeste de la Provincia de Catamarca (Argentina).

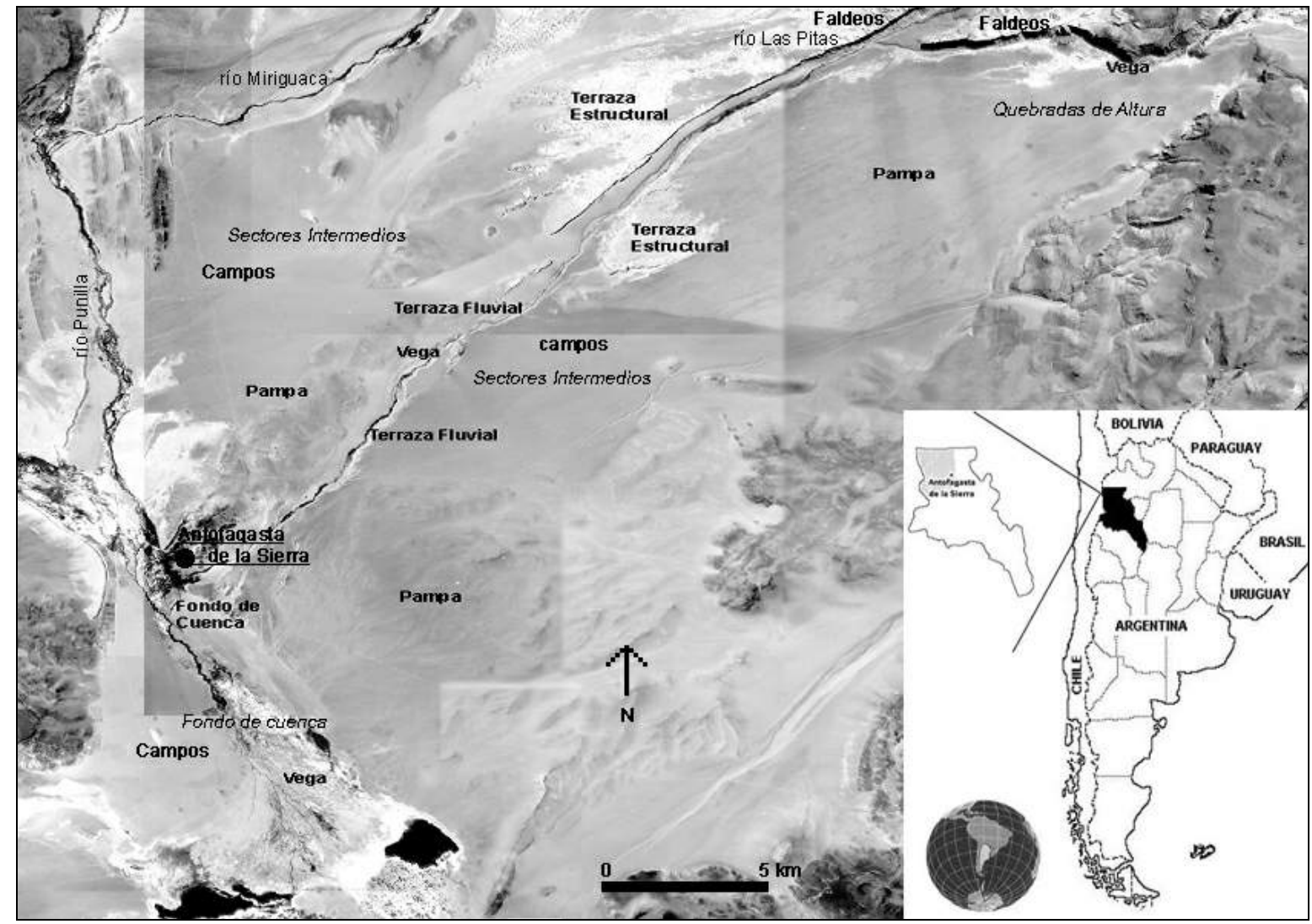

FIGURA 1. Localización de la Puna Meridional argentina: unidades del paisaje

Se trata de un enclave caracterizado por una: a) intensa radiación solar a causa de su altitud sobre el nivel del mar (ca. 3400 - 4600 m snm.), b) gran amplitud térmica diaria (cuyo promedio anual oscila entre los -5 y $32^{\circ} \mathrm{C}$ ), c) marcada estacionalidad, d) escasez de precipitaciones (en torno a los $150 \mathrm{~mm}$ anuales), e) baja presión atmosférica (próxima a los 640 hectopascales) y f) irregular distribución de recursos.

La fauna autóctona está constituida por mamíferos entre los que se encuentran roedores como la chinchilla (Chinchilla brevicaudata), la vizcacha de la puna (Lagidium viscacia), el tuco-tuco (Ctenomys sp.), la vizcacha serrana (Lagiduim 
viscacia) entre otros taxones de tamaños pequeños. Además de pumas (Felis concolor), zorros colorado y gris (Pseudalopex culpaeus y P. griseus), zorrinos (Conepatus sp.), quirquinchos (Dasypus sp.), llamas (Lama glama) y vicuñas (Lama vicugna).

La diversidad de aves es muy alta, pudiéndose mencionar el suri o ñandú (Pterocnemia pennata), la perdiz andina (Tynamotis pentlandii), los flamencos (Phoenicoparrus andinus, Ph. jamesi, Phoenicopterus chilensis), las guayatas (Chloephaga melanoptera), el cóndor (Vultur gryphus) y otros falconiformes. Asimismo, se encuentran algunos reptiles y batracios endémicos (Dirección de Flora y Fauna Silvestres, 2000).

Por tratarse de un desierto de altura, la diversidad y la abundancia de recursos bióticos son bajas y su distribución heterogénea. Por tal motivo, se distinguen áreas con alta concentración de especimenes frente a otras en los que se encuentran sumamente muy dispersos, o son inexistentes.

El panorama fitogeográfico comprende comunidades vegetales cuya composición y abundancia varía de acuerdo con el gradiente altitudinal y con la distancia a los exiguos cuerpos y flujos de agua; pudiéndose diferenciar una vegetación de tipo disperso, propia de faldeos de quebradas, campos y pampas, y otra de tipo agrupado, propio de los sectores de vega (Haber, 1991) (Figura 1); ofreciendo, cada uno de ellos un diferente potencial forrajero.

Los suelos, poco desarrollados, influyen directamente en la baja capacidad de respuesta que tienen los ecosistemas naturales frente a las perturbaciones, tanto naturales como antrópicas que pudieran ocurrir. A esto se suma el hecho de que la escasa cobertura vegetal tampoco contribuye a contrarrestar el accionar de distintos agentes erosivos, principalmente de los vientos.

\section{Metodología utilizada}

Las investigaciones de campo fueron realizadas en la localidad de Antofagasta de la Sierra, durante los años 1996 y 2002, entendiendo que el espacio puede ser aprehendido y analizado a través de la definición de paisajes, que se manifiestan como una sucesión de fisonomías particulares (Riesco, 1982), y de la 
noción de distancia entre diferentes localizaciones (Dollfus, 1977), entendidas en el sentido de puntos ubicados sobre el terreno. La operativización de ambos conceptos requiere, pues de la introducción de distintas escalas espaciales, las cuales contribuyen a la resolución de las estrategias de uso de la tierra implementadas por las poblaciones humanas y de los impactos ocurridos a partir de ellas.

La micro-escala contribuye a la identificación e interpretación de las formas de uso de geoformas, suelos, flora y fauna en localizaciones puntuales, tales como puestos de pastoreo, residencias de campo y en el conglomerado urbano de la villa. La meso-escala permite acceder a un conocimiento regional acerca de la composición y manejo de pasturas y rebaños. La macro-escala comprende a las áreas vecinas, tales como la puna seca, los sectores de valles y quebradas y de valles con los que los antofagasteños mantienen diferentes tipos de interacciones. Extendiéndose, incluso a los empresarios residentes en otras provincias del país. Por último, la mega-escala se expresa a través de las interrelaciones comerciales establecidas o proyectadas con mercados del exterior y de los alcances de las normativas legales vigentes, inscriptas en el derecho internacional.

La TABLA 1 presenta las variables consideradas y sus niveles de medición.

\begin{tabular}{|c|c|c|c|}
\hline Tipo de Variable & Variable & Indicadores & Escala \\
\hline \multirow{3}{*}{ Culturales } & Usos del espacio & $\begin{array}{l}\text { unidades residenciales } \\
\text { puestos } \\
\text { campos de pastoreo } \\
\text { sembradíos } \\
\text { áreas de riego }\end{array}$ & Nominal \\
\hline & Circulación de bienes & $\begin{array}{l}\text { compra-venta } \\
\text { trueque }\end{array}$ & Nominal \\
\hline & Procesos productivos & $\begin{array}{l}\text { tecnologías tradicionales } \\
\text { conocimientos tradicionales } \\
\text { herramientas industrializadas } \\
\text { recursos autóctonos } \\
\text { recursos exóticos }\end{array}$ & Nominal \\
\hline \multirow{2}{*}{ Demográficas } & $\begin{array}{l}\text { Cantidad de } \\
\text { individuos }\end{array}$ & $\begin{array}{l}\text { sexos } \\
\text { edades }\end{array}$ & $\begin{array}{l}\text { Nominal } \\
\text { Intervalos }\end{array}$ \\
\hline & Educación & $\begin{array}{l}\text { analfabetos } \\
\text { nivel de escolarización }\end{array}$ & Nominal \\
\hline Económicas & Actividades & $\begin{array}{l}\text { administración pública } \\
\text { productores } \\
\text { comerciantes } \\
\text { sin ocupación }\end{array}$ & Nominal \\
\hline \multirow[t]{2}{*}{ Jurídicas } & Tenencia de la Tierra & $\begin{array}{l}\text { fiscales } \\
\text { escrituradas }\end{array}$ & Nominal \\
\hline & Topografía & niveles altitudinales & Intervalos \\
\hline
\end{tabular}




\begin{tabular}{|l|l|l|l|}
\hline & Geoformas & $\begin{array}{l}\text { planicie de inundación } \\
\text { terraza estructural } \\
\text { campos } \\
\text { pampas } \\
\text { faldeos }\end{array}$ & Nominal \\
\cline { 2 - 4 } & Suelos & $\begin{array}{l}\text { drenaje } \\
\text { fertilidad } \\
\text { erosión } \\
\text { salinidad }\end{array}$ & Nominal \\
\hline \multirow{2}{*}{ Ambientales } & Comunidades vegetales & $\begin{array}{l}\text { especies } \\
\text { cobertura }\end{array}$ & $\begin{array}{l}\text { Nominal } \\
\text { Intervalos }\end{array}$ \\
\cline { 2 - 4 } & Comunidades animales & $\begin{array}{l}\text { fredadores silvestre (autóctona / introducida) } \\
\text { fauna domesticada (autóctona } \\
\text { introducida) }\end{array}$ & Nominal \\
\hline
\end{tabular}

TABLA 1. Variables y niveles de medición

Distintas aproximaciones geográficas fueron realizadas a partir de la carta geográfica IGM (Instituto Geográfico Militar), Antofagasta de la Sierra, escala 1:100.000. Mientras que las distintas unidades del paisaje fueron identificadas sobre fotografías aéreas SEGEMAR (Servicio Geológico Minero Argentino), escala 1:10.000.

Los muestreos de comunidades vegetales tuvieron por finalidad dar indicios del potencial de este recurso y de su distribución sobre el terreno. Debido a la ausencia de estudios específicos se procedió a reconocer, en un nivel de definición muy primario, las especies representadas, su localización por sector altitudinal fondo de cuenca, sectores intermedios y quebradas de altura-, grado de dispersión I agrupación y posibles usos locales. El estado de conservación de las mismas permitió calibrar tanto la incidencia de la explotación de los recursos vegetales como de los impactos ocurridos a causa de la erosión de los suelos en los sectores donde la cobertura vegetal era escasa o nula.

La composición y características de los rebaños fueron registradas mediante el conteo de animales en explotaciones de pastores locales, a la vez que otros fueron tomados de una consulta realizada por la Municipalidad de Antofagasta de la Sierra (Gentileza Tco. Agrónomo Lucas Soriano).

La indagación y el registro de conocimientos, opiniones y actitudes entre los pobladores locales fueron realizadas a través de entrevistas a productores locales, administradores municipales y empresarios criadores de llamas. 
Las entrevistas a productores tuvieron lugar entre aquellas personas que accedieron a responder a una serie de preguntas abiertas, referidas en todos los casos a: a) formas de acceso y tenencia de la tierra, b) extensión de las tierras, c) composición de las unidades domésticas, d) estructura de los rebaños, e) criterios de selección para reproducir / sacrificar animales, f) disponibilidad y explotación de pasturas y g) causas de muertes de animales. Las preguntas efectuadas a administradores municipales y a empresarios fueron menos pautadas y estuvieron dirigidas a conocer sus apreciaciones acerca del manejo actual de los rebaños y las propuestas y expectativas de un manejo comercial de los mismos.

En situaciones específicas, tales como fiestas en el pueblo y la celebración de distintas ediciones de la Feria de la Puna, los datos fueron recolectados a través de la observación directa.

Un conjunto de información fue obtenido de la consulta de censos y estadísticas generados por el INDEC (Instituto Nacional de Estadísticas y Censos), la Secretaría de Estadísticas y Censos de la Provincia de Catamarca y la Municipalidad de Antofagasta de la Sierra.

Por último, las reglamentaciones correspondientes a recursos tradicionales, fauna silvestre, conservación de ambientes naturales y suelos fueron consultadas a través de la Constitución Nacional de la República Argentina, la constitución de la Provincia de Catamarca, leyes suscritas por la Provincia de Catamarca y Convenciones Internacionales.

\section{Acceso y formas de uso del espacio}

La tenencia de la tierra es, en algunos sectores, de carácter formal contándose con escrituras. Esta es la situación en que se encuentran las casas de la Villa y los lotes localizados en sus inmediaciones, conocidos como Vega del Pueblo y de La Banda. Mientras que en los demás casos, en los que se inscriben la mayor parte de las tierras utilizadas por los productores locales, la tenencia es informal, negociada en base a usos consuetudinarios o de hecho; siendo reclamada su posesión en base a criterios de primogenitura. 
El derecho a la tierra, incluso de las fiscales, es obtenido por herencia o por compra-venta avalada por el juez de paz local, pero en ningún caso estas transacciones quedan registradas en catastros.

La extensión de los terrenos ocupados por las distintas familias, ya ha sido negociada o por lo menos se encuentra actualmente definida, puesto que cada poblador conoce y le son reconocidos los límites de sus terrenos.

Pese al hecho de reconocerse los límites y las extensiones más o menos precisos de las distintas parcelas, estos no interfieren en la trashumancia de pastores y rebaños. Momento durante el cual no sólo son atravesadas las tierras que pertenecen a otras personas, sino que también les está permitido a los pastores durante la marcha, hacer noche en los puestos dispersos entre los campos y que sus animales consuman las pasturas existentes. Los caminos utilizados están pautados, siguiendo recorridos que unen puntos previamente determinados, tales como ciénagos, aguadas y puestos.

La mayor parte de las unidades domésticas o familiares residen en la Villa de Antofagasta de la Sierra. Sin embargo se observan excepciones, ya que es posible encontrar familias que residen fuera del predio de la misma, en lo que se denomina "el campo". Tanto unos y otros, además de las residencias familiares cuentan con por lo menos uno o dos puestos localizados en distintos sectores de la Puna.

Los puestos son estructuras de construcción muy simple, conformados por recintos dispersos entre áreas de pastoreo y a cierta distancia de los lugares de residencia familiar. En general, consisten en un recinto techado, una cocina sin techo y un corral.

La finalidad de los puestos es proporcionar un refugio en donde permanecer y reunir a los animales durante un muy breve período de tiempo. En ocasiones vinculados con actividades de esquila, de señalada o marcado de ejemplares, de carneo o de rotación de rebaños entre áreas de pastoreo.

La Villa de Antofagasta de la Sierra, por su parte, funciona como centro de servicios en donde tienen lugar múltiples actividades. Algunas de ellas relacionadas con la asistencia educativa, sanitaria y la seguridad, con las comunicaciones y la administración pública, las fiestas patronales y los actos políticos, el intercambio comercial y de información, el albergue y la provisión de alimentos y de materiales. 
Los habitantes que residen en ella de modo permanente son los docentes y los empleados de la administración pública, mientras que otros, que tienen una mejor posición económica, tales como comerciantes importantes, grandes productores y políticos locales, lo hacen de forma semi-permanente, contando con otra residencia en la localidad de El Peñón, en las ciudades de Belén, San Fernando del Valle de Catamarca, o en algún otro punto productivo provisto por una importante disponibilidad de pasturas, como las vegas de Calalaste, Curuto, etc.

En el ejido de la Villa se observan viviendas, generalmente conformadas por 5 o 6 habitaciones, dos de las cuales, generalmente de grandes dimensiones, alrededor de los 4 × 6 m., dan al frente o a la calle, dispuestas una a continuación de la otra. El uso otorgado a cada recinto es altamente variable, ya que pueden funcionar por breves lapsos como sala o lugar de reunión, local comercial o salón de venta, lugares de almacenaje, dormitorios, e incluso ser rentadas a terceros como habitaciones. Por detrás se dispone un patio central de planta rectangular, de unos 12 m. x 6 m., en cuyos laterales se disponen una serie de cuartos más pequeños, la cocina y más lejos se ubican las instalaciones sanitarias.

Una clase de vivienda diferente está conformada por habitaciones rectangulares de dimensiones menores a los $6 \mathrm{~m}$. de lado, utilizadas como dormitorios, cocina o depósito, por delante o por detrás es frecuente observar una pequeña huerta, en donde se cultivan algunas hortalizas y crecen árboles frutales, y en un lugar bien alejado del resto de las construcciones se encuentran los sanitarios o letrinas.

En las áreas circundantes al conglomerado urbano de Antofagasta predominan las actividades rurales. Las viviendas que allí se encuentran conforman unidades independientes, donde el tamaño de las habitaciones es semejante a las anteriores pero en un número más reducido. Con frecuencia, contiguo a la casa se dispone el corral y el horno de barro. En esta clase de construcciones el patio puede no estar delimitado, quedando comprendido por el espacio que debe recorrerse para desplazarse de un recinto a otro.

Por último, un tipo de recinto muy precario, también presente en las áreas rurales, son los refugios utilizados durante la marcha. Estos comprenden únicamente un pircado rectangular y un techado parcial hecho con unas cuantas ramas, que sólo son eficientes para ponerse al resguardo de los vientos. 
Las pocas extensiones de tierra que son dedicadas al cultivo se localizan en las áreas adyacentes a los cursos de los ríos, por tratarse de los sectores mejor irrigados de forma natural o de aquellos que pueden ser regados mediante inundación, y están dedicados al cultivo de alfalfa o a extender los pastos que crecen en las márgenes de los cuerpos de agua.

Asimismo, en ciertos sectores se ha observado que son realizadas actividades simbólicas, cuya evidencia material está comprendida por la colocación de perros muertos debajo de grandes bloques cercanos a lugares con arte rupestre prehispánico y las cruces pintadas con la sangre de los animales carneados en las paredes de los corrales.

Todo esto indica que no parecen haber sectores del espacio que no estén en uso, a pesar de no encontrarse construidos. En general, la existencia de agua y pastos parecerían encontrarse entre los elementos principales para constituirse en factores de localización, transito y uso.

\section{La economía local}

Las unidades domésticas de producción están constituidas por parientes directos, niños criados en su seno y ahijados. Entre unos 5 a 8 individuos co-habitan en un mismo lugar de residencia, siendo ó 3 personas adultas y el restos niños o adolescentes. Todos ellos, participan en diferente forma y medida de las labores productivas.

La economía del área se orienta básicamente hacia la autosubsistencia de la unidad doméstica o familiar y se circunscribe en torno a las actividades de pastoreo, en las que se encuentra involucrada entre el 90 o $95 \%$ de la población del Departamento de Antofagasta de la Sierra, incluyendo a las localidades de El Peñón, Antofagasta de la Sierra, el Salar de Hombre Muerto y Antofalla.

La meta de la producción doméstica es garantizar el ideal andino de conformar unidades autosuficientes, mediante la obtención de carne fresca o charqueada, leche, quesos, morcillas, lana y cueros y la extracción de otros recursos del entorno circundante a través de la caza o de la recolección. La generación de excedentes no es una finalidad en sí misma, aunque resulta importante para realizar 
alguna venta o trueque por elementos industrializados -pe, azúcar, yerba mate, ropa, harina. etc.- o no producidos por la familia.

El porcentaje de población restante se encuentra ocupada en la administración municipal, en la docencia, en la Policía Provincial y en la Gendarmería Nacional. Con excepción de los empleados municipales y de algunos oficiales de la policía, los docentes y los gendarmes no son nativos de Antofagasta, sino que provienen desde otros departamentos de la provincia de Catamarca en el primer caso y de otras provincias en el segundo.

Una pequeña parte de la población trabajadora cuenta con algún nivel de escolarización. Tendencia que se está revirtiendo en el transcurso del tiempo a partir de la instalación de la escuela primaria y de la apertura del secundario. Ahora bien, precisamente quienes acceden a un título secundario son los que migran a la capital provincial o a la ciudad de Belén para continuar sus estudios superiores o para buscar mejores posibilidades laborales.

La calificación laboral de los productores es adquirida mediante el aprendizaje directo al participar de las actividades productivas, lo cual tiene la faceta positiva de contribuir a la transmisión de conocimientos tradicionales y la negativa de afianzar ciertos rasgos problemáticos en la elaboración de ciertas producciones artesanales (Ver más adelante, Punto 8.4).

El acceso a moneda es posible sólo para algunos habitantes de la Puna, lo cual no solamente depende de la producción de excedentes dentro de la unidad doméstica, sino que también se de la posibilidad de encontrar un potencial comprador que disponga de dinero. En la comunidad antofagasteña exclusivamente cuentan con disponibilidad de moneda o cuasi-monedas (bonos provinciales de curso legal hasta el año 2002) aquellos que logran emplearse en puestos administrativos, quienes son propietarios de almacenes de ramos generales, los vendedores trashumantes y los forasteros que esporádicamente arriban al área.

Las escasas posibilidades que tienen las familias de absorber un eventual crecimiento de las mismas junto con la confrontación con otros modelos de vida citadinos y la necesidad de manejo de moneda, llevan a una intensa migración de jóvenes de ambos sexos hacia otros departamento de la provincia como a otros puntos del país. 
Los efectos negativos de este intenso proceso migratorio se manifiestan en el abandono de las prácticas pastoriles, de los conocimientos y usos de tecnologías tradicionales y en el envejecimiento de la población. Al mismo tiempo que el despoblamiento de los espacios más alejados de la Villa -ca. 20 km- tales como los sectores de quebradas de altura, registran la presencia y el ulterior avance de los predadores naturales (pumas y zorros) hacia en las inmediaciones del poblado.

\section{Recursos producidos y recolectados}

Los animales de rebaño comprenden tanto fauna autóctona, como la llama, y especies introducidas o exóticas de pequeños rumiantes, entre los que se cuentan cabras y ovejas.

En algunos casos los pastores puneños propician rebaños solamente de ovicápridos, a la vez que en otros, a estos animales se les suma la presencia de camélidos domesticados. A pesar de las diferencias etológicas y de tamaño corporal existentes entre las distintas especies, ambas pueden pastar juntas. Sea durante todo el año o estacionalmente, dependiendo exclusivamente de los criterios de cada productor.

Los animales pastan libremente siguiendo recorridos bastante pautados. Son escasos los pobladores que cuentan con algún tipo de encierro, motivo por el cual es frecuente que las cabras se "vayan al cerro" acompañadas por "ovejas cabreras" y haya que ir a buscarlas antes de que mueran de frío en el invierno o sean presas de zorros y pumas.

Los animales, más allá del hecho de estar literalmente sueltos, son rotados estacionalmente entre las pasturas que las familias tienen en propiedad o que son arrendadas a terceros, las cuales pueden estar espacialmente separadas por una 0 dos jornadas de marcha.

En la mayoría de los casos, los pastos consumidos por los rebaños son los que crecen naturalmente. No obstante, una minoría de productores cuenta con alguna clase de complemento vegetal -alfalfa cultivada- para las épocas invernales, en las que los pastos son escasos. Pocos también son quienes vigilan de manera 
directa o contratan "guardianes" para que cuiden a los animales del accionar de los predadores.

Los pobladores utilizan, además, una serie de recursos que extraen del ambiente. Entre estos se encuentran los huevos de aves, la pesca de truchas introducidas en algunos cursos de agua- y la recolección de vegetales, todos ellos destinados al consumo humano. Otras actividades se orientan a la obtención de materiales de origen mineral, tales como rocas y arcillas para la construcción, y a la captura de animales silvestres, ya sea por su carne, cuero, plumas o lana, o por tratarse de predadores que actúan contra la hacienda. Cabe mencionar que algunas de las especies capturadas se encuentran protegidas, constando en diferentes apéndices (I y II) del Convenio Cites (1973) (pe. chinchilla I, suri I, vicuña I / II, puma, zorro colorado y gris II).

\section{Acciones institucionales para el desarrollo económico de la Puna}

Históricamente, los principales centros de explotación agrícola-ganadera se ubicaron en la Pampa Húmeda, a más de 1500 km de distancia de la Puna catamarqueña. A nivel regional, los más altos rendimientos de la producción agrícola se obtienen en las zonas aledañas al ambiente puneño, en las localidades de Belén y de Catamarca, motivo por el cual este área quedó una vez más relegada de las propuestas de integración socioeconómica.

Desde 1973 a la fecha, a través de las distintas medidas económicas y políticas, el gobierno provincial propicia la reactivación económica y la promoción social de la Provincia, sin embargo, estas propuestas continúan ubicando a la Puna en un rol marginal (Plan Estratégico Consensuado, 1996).

En la década de los '80 la Municipalidad de Antofagasta de la Sierra realizó algunas acciones para mejorar la calidad de los rebaños ovinos y aumentar sus posibilidades de colocación en el mercado. Por medio de la Dirección de Agrotécnia fueron comprados reproductores Lincoln, Corriedale y Merino para cruzar con las ovejas criollas, criadas por los pobladores.

Los resultados indican que, solamente las ovejas Merino se adaptaron a la rigurosidad del ambiente puneño y en cuanto a la participación de la comunidad 
antofagasteña, la propuesta se descontroló, porque aquellos productores que disponían de capital trajeron sus propios reproductores y con ellos enfermedades parasitarias hasta entonces desconocidas en la región (Com. Pers. Tco. Agrónomo Lucas Soriano, 1995)

Posteriormente, en los años '90 el gobierno provincial, a través del Ministerio de Producción de la Provincia de Catamarca y la Municipalidad de Antofagasta de la Sierra, generó otra propuesta de gestión intentando revalorizar los sistemas productivos tradicionales y destacando la incidencia económica y ambiental positiva que tendría la explotación de recursos autóctonos. Entre los recursos identificados se encuentra la cría de llamas, por su carne, lana y como mascota, y los encierros y esquila de vicuñas.

La meta concreta es alcanzar el mercando internacional de lana dadas las aptitudes naturales de las fibras de camélidos y de los altos precios existentes. Dentro de ese contexto, a través de la Dirección de Agrotécnia, del INTA (Instituto Nacional de Tecnología Agrícola) y del SENASA (Secretaría Nacional de Sanidad Animal) se propicia la celebración de distintas ediciones anuales de la Feria de la Puna; previendo que esta puede ser un incentivo indirecto para inducir a los productores a reproducir en sus rebaños los criterios de producción del mercado.

En la exposición ganadera no son consideradas las cabras y las ovejas son juzgadas por lote, dentro de los corrales pero no participan de las ceremonias de premiación. Solamente participan diversos lotes de llamas, las que individualmente acceden a la pista de juzgamiento y son premiadas con cucardas y certificados extendidos a sus propietarios.

La razón de la elección de campeones es inducir a los pastores para que vayan reconociendo, a través del tiempo, los criterios de selección que son acordes a las expectativas del mercado de lanas y que en el transcurso de Ferias sucesivas se vayan homogeneizando los rebaños de llamas.

En consecuencia, a través de los campeones se espera instaurar el modelo a seguir al momento de realizar decisiones acerca de qué ejemplares reproducir, castrar o sacrificar. El fin explícito es que los productores reconozcan en sus rebaños los criterios buscados por los organizadores y empresarios y traten de multiplicarlo. 
Como la propuesta está orientada a la explotación lanar, los estándares de selección están relacionados con la estructura, uniformidad y color de la fibra; restándole importancia a otros rasgos morfotípicos, también altamente valorizables, como serían la distribución muscular para la producción de carnes o de animales manchados -pintados- o de tamaños extremos -pequeños o grandes- como mascotas.

Los pastores, por su parte, consideran que es el color blanco de la lana el que deberían propiciar, debido a que este criterio es acorde con un esquema simbólico de profundo arraigo en la tradición andina, sacrificando, por lo general, a los machos negros. Esta decisión se contrapone, de modo directo con los criterios del mercado, dado que en la actualidad se encuentra un mayor precio en la fibra de color negro, seguida por el beige o color vicuña. Asimismo, los productores locales entienden que los animales manchados pueden ser esquilados a mano separando la lana mancha por mancha, pero esta percepción tampoco resulta eficiente en el mercado de lanas, orientado obtener homogeneidad en los mantos de los animales y a acelerar el proceso de esquila.

Los resultados esperados, por los empresarios y el poder político, son optimistas en cuanto al impacto positivo que tendrá la explotación de fibra de camélidos, previendo que el alto precio internacional que podría alcanzar la venta de lana elevará, como consecuencia necesaria ${ }^{1}$ el nivel de vida de los habitantes de la Puna. A la vez que consideran que las modificaciones de las pautas productivas tradicionales repercutirán favorablemente sobre el ecosistema puneño, al disminuir el impacto negativo que, a su criterio, tienen los ovicápridos sobre las pasturas, a causa del pisoteo y de sus formas particulares de consumo de pastos.

\section{Diagnóstico social y medioambiental}

Este sector de Puna registra, desde tiempos prehistóricos, una intensa y sostenida explotación de los recursos naturales, lo cual ha producido diversas clases de interacciones entre poblaciones humanas y los ecosistemas nativos. Situación, que al parecer no tuvo un mayor impacto negativo sobre el ambiente.

\footnotetext{
${ }^{1}$ En la jerga económica más ortodoxa se espera que la inversión de capitales en un sector "permeé" naturalmente hacia los niveles más bajos de la cadena productiva o de la sociedad. 
Es un hecho que las actuales actividades productivas en Antofagasta de la Sierra no coiciden con los modelos de rentabilidad económica. Si bien las decisiones económicas realizadas por los pobladores locales parecen ser acertadas en cuanto garantizan la biodiversidad del ambiente, son acordes con los conocimientos tradicionales y permiten perpetuar la producción doméstica, no resultan aptas para el cobro de impuestos, ni con los intentos del poder político provincial y municipal por introducir la necesidad de solicitar préstamos bancarios.

En consecuencia, los proyectos oficiales, que cuentan con la intervención de empresarios, tienen por finalidad instaurar un nuevo modelo de explotación ganadera. Para eso argumentan que el actual uso de los recursos naturales no es ambientalmente sostenible, a causa de los efectos negativos que tendrían las prácticas de pastoreo de rebaños mixtos.

La concreción de este proyecto implica profundos cambios en la estructura ambiental y social de la comunidad antofagasteña. Sin embargo, tanto el deterioro ambiental que se le atribuye a las actuales prácticas productivas como a los futuros impactos que podría tener este nuevo emprendimiento textil, no pueden ser evaluados sin un diagnóstico previo de la presente situación socio-ambiental. Por este motivo, se propuso realizar una evaluación de los recursos naturales y del suelo, teniendo por meta puntualizar cada uno de los usos actuales, calibrar sus efectos y proponer algunas posibilidades de uso potencial dentro de un esquema de desarrollo sustentable.

En la TABLA 2 se presenta una apreciación cualitativa de los recursos naturales en cuanto a sus usos dentro de la comunidad local, potencialidades no desarrolladas, relaciones ecosistémicas y referencias a normativas vigentes. 


\begin{tabular}{|c|c|c|c|c|c|}
\hline & Suelos & Agua & \begin{tabular}{|l|} 
Fauna \\
Silvestre
\end{tabular} & \begin{tabular}{|l|} 
Fauna \\
Domesticada \\
\end{tabular} & Flora \\
\hline $\begin{array}{l}\text { Características } \\
\text { sobresalientes }\end{array}$ & $\begin{array}{l}\text { Poco } \\
\text { desarrollados }\end{array}$ & $\begin{array}{l}\text { Hace posible } \\
\text { la actividad } \\
\text { biótica }\end{array}$ & $\begin{array}{l}\text { lana (vicuña) } \\
\text { cueros (vicuña } \\
\text { chinchíllidos) } \\
\text { plumas (suri) }\end{array}$ & $\begin{array}{lr}\text { carne y lana } \\
\text { (ovicápridos y } \\
\text { llamas) } \\
\text { transporte } \\
\text { (caballo, mulas } \\
\text { y burros) }\end{array}$ & $\begin{array}{l}\text { combustible, } \\
\text { forraje, } \\
\text { medicinales }\end{array}$ \\
\hline Valor comercial & Bajo & No estimado & Medio /Alto & Medio / Alto & Medio \\
\hline Explotada desde & \multicolumn{3}{|c|}{ Tiempos prehispánicos } & $\begin{array}{l}\text { A excepción de } \\
\text { la llama a partir } \\
\text { de la conquista } \\
\text { española }\end{array}$ & $\begin{array}{l}\text { Tiempos } \\
\text { prehispánicos }\end{array}$ \\
\hline $\begin{array}{ll}\text { Formas } & \text { de } \\
\text { explotación } & \end{array}$ & \multicolumn{5}{|l|}{ Tradicionales } \\
\hline Normativa legal & $\begin{array}{l}\text { De hecho, } \\
\text { pocos casos } \\
\text { con escrituras }\end{array}$ & $\begin{array}{l}\text { Administración } \\
\text { municipal }\end{array}$ & $\begin{array}{l}\text { Si } \\
\text { (varias } \\
\text { especies } \\
\text { endémicas) }\end{array}$ & No & No \\
\hline $\begin{array}{l}\text { Variaciones en la } \\
\text { Distribución }\end{array}$ & Escasa & Nula & Nula & Alta & Nula / Escasa \\
\hline Compite con & $\begin{array}{l}\text { Demás } \\
\text { herederos }\end{array}$ & Nada & \begin{tabular}{|l|} 
Fauna de \\
origen exótico
\end{tabular} & $\begin{array}{l}\text { Fauna } \\
\text { autóctona }\end{array}$ & Nada \\
\hline $\begin{array}{l}\text { Producción } \\
\text { actual }\end{array}$ & \multicolumn{5}{|c|}{ De subsistencia, no competitiva } \\
\hline $\begin{array}{ll}\text { Mantener } & \text { su } \\
\text { forma actual de } \\
\text { producción }\end{array}$ & \multicolumn{5}{|c|}{$\begin{array}{l}\text { A nivel unidad doméstica, es posible } \\
\text { A nivel regional y provincial, no genera ganancias }\end{array}$} \\
\hline $\begin{array}{l}\text { Posibilidad de } \\
\text { comercialización }\end{array}$ & Escasa & Nula & Alta & $\begin{array}{l}\text { Alta las llamas } \\
\text { únicamente, los } \\
\text { restantes Bajo }\end{array}$ & Nula / Escasa \\
\hline
\end{tabular}

TABLA 2. Evaluación cualitativa de los recursos naturales

\subsection{Recursos hídricos y suelos}

El manejo del agua se refiere a las acciones orientadas a aumentar las superficies irrigadas por inundación con la finalidad de extender la cobertura vegetal, teniendo como valor emergente su contribución al retrazo de la erosión ocasionada por el flujo del torrente fluvial. Evidencias de erosión hídrica se observan en los meandros que describe el curso del río Las Pitas, la que se ha intentado disminuir mediante la disposición de arbustos cortados y enterrados para inhibir el lavado de los suelos y aumentar la fijación de sedimentos.

El manejo de las cuencas de los ríos Punilla y Las Pitas para el riego parece ser eficiente, ya que permite aumentar la cobertura vegetal sobre ambas márgenes. Sin embargo, en la Vega de la Banda, localizada frente a la Villa de Antofagasta, 
este procedimiento dio origen a la aparición de sectores salinizados que son lamidos por los camélidos, pero cuyo impacto necesita de controles específicos de su evolución.

Estas acciones son supervisadas desde el ámbito municipal y a pesar de no ser óptimas resultan valiosas, dada la escasa disponibilidad técnica y económica existente. Asimismo, la percepción de los pobladores de dicha práctica es positiva, dado que durante el invierno a causa del congelamiento del agua que se endica sobre la planicie de inundación contribuye a controlar las plagas de langostas, al dañar la depositación de huevos y de larvas limitando su reproducción.

La pérdida de agua por evaporación ha sido manejada solamente de forma individual por un productor local residente en el sector intermedio -Peñas Coloradasmediante la rectificación del cauce del río Las Pitas. Resulta previsible que su incidencia sea positiva, debido a que disminuye las posibilidades de infiltración y evaporación propiciada por los meandros que describen los cursos fluviales y la potente matriz arenosa de los suelos que atraviesa.

Los suelos se observan en general bien conservados, salvo algunos sectores en donde se registran algunos focos erosivos, tales como los revolcaderos de camélidos identificados en los sectores de quebradas de alturas y los efectos del pisoteo de ovicápridos, como consecuencia de la fuerte circunscripción espacial a la que son sometidos estos rebaños en el sector intermedio del río Las Pitas.

La capacidad de uso de la tierra es evaluada en la TABLA 3, diferenciando geoformas y unidades del paisaje (FIGURA 1) y teniendo en cuenta: a) la capacidad productiva para usos agrícolas, ganaderos, asentamientos humanos, etc., b) vocación de uso, se refiere al uso que se considera apropiado y que puede no coincidir con el otorgado en la actualidad, c) sobre-uso, alude a tierras que son utilizadas más allá de su capacidad productiva y d) sub-utilizadas, cuando los terrenos son usados en actividades que se ubican por debajo de su capacidad productiva (sensu Mora Carpio 2000). 


\begin{tabular}{|c|c|c|c|c|c|}
\hline & Actividad & Sustentable & Vocación de uso & Sobreuso & Subutilizada \\
\hline $\begin{array}{l}\text { Planicies de } \\
\text { inundación (vega) }\end{array}$ & $\begin{array}{l}\text { Pastoreo } \\
\text { Riego }\end{array}$ & $\begin{array}{l}\text { Regular } \\
\mathrm{Si}\end{array}$ & Ninguna & $\begin{array}{l}\text { En algunos } \\
\text { sectores }\end{array}$ & No \\
\hline Fondo de cuenca & Asentamiento & Regular & Ninguna & No & No \\
\hline Terrazas fluviales & $\begin{array}{l}\text { Pastoreo } \\
\text { Riego } \\
\text { Asentamiento } \\
\text { Cultivos } \\
\text { Recolección }\end{array}$ & $\begin{array}{l}\text { Regular } \\
\mathrm{Si} \\
\mathrm{Si} \\
\mathrm{Si} \\
\mathrm{Si}\end{array}$ & Ninguna & $\begin{array}{l}\text { En algunos } \\
\text { sectores }\end{array}$ & No \\
\hline $\begin{array}{l}\text { Terrazas } \\
\text { estructurales } \\
\text { y faldeos de } \\
\text { quebradas }\end{array}$ & $\begin{array}{ll}\text { Pastoreo } & \\
\text { Recolección } & \\
\text { Extracción de } \\
\text { arcillas y } \\
\text { piedras }\end{array}$ & $\begin{array}{l}\mathrm{Si} \\
\mathrm{Si} \\
\mathrm{Si}\end{array}$ & Ninguna & No & No \\
\hline $\begin{array}{l}\text { Pampas (Glacis) } \\
\text { y campos }\end{array}$ & $\begin{array}{l}\text { Pastoreo } \\
\text { Asentamiento } \\
\text { Recolección } \\
\text { Extracción de } \\
\text { arcillas y } \\
\text { piedras }\end{array}$ & $\begin{array}{l}\mathrm{Si} \\
\mathrm{Si} \\
\mathrm{Si} \\
\mathrm{Si}\end{array}$ & Ninguna & No & No \\
\hline
\end{tabular}

TABLA 3. Capacidad de uso del suelo

La información presentada permite sostener que las actividades productivas y extractivas practicadas tienen un escaso impacto negativo sobre el ambiente. Lo cual parece estar vinculado a la escasa presión que ejerce el modelo de explotación económica implementado, al estar exclusivamente orientado a la satisfacción de necesidades básicas de autosuficiencia doméstica, a lo que se suman la baja demografía existente -ca 950 habitantes (INDEC, 1997)-, al patrón disperso del asentamiento -densidad poblacional de $0.03 \mathrm{Hab} / \mathrm{Km}^{2}$ (INDEC, 1997)- y al uso de tecnologías tradicionales en la explotación de recursos naturales que resultan amigables al ambiente por ser específicamente diseñadas para interactuar con este particular tipo de ecosistema y por haber sido extensamente probadas en el transcurso de los tiempos, a la vez que producen un bajo nivel de contaminación.

La generación de residuos sólidos por habitante, en términos netamente cuantitativos, no parece marcar una tendencia en aumento, debido a las escasas posibilidades de consumo existentes. El problema que presentan los descartes en la Puna es su lenta degradación a causa de la extrema sequedad del ambiente, por lo que tienen una muy alta tasa de perduración tanto al ser dispuestos a cielo abierto como al ser enterrados en basurales. 
Es posible que la composición de los descartes haya variado en los últimos 20 años. El punto de inflexión tal vez se encuentre en la apertura de la ruta provincial $\mathrm{N}^{0}$ 43. Momento, a partir de cual, se agilizó el acceso, para algunos de los miembros de la comunidad, de productos industrializados con envases plásticos, metálicos y de vidrio.

En las afueras de la Villa, en las inmediaciones del cementerio, se localiza un incipiente basural a cielo abierto en donde se observa una importante acumulación de bolsas plásticas. Los basurales localizados en relación a las residencias de campo y a los puestos no siempre están enterrados, pudiéndose ver que se encuentran constituido, básicamente, por desechos orgánicos, donde resultan evidentes las acumulaciones de huesos de animales carneados.

\subsection{Recursos vegetales}

En el fondo de cuenca, entre los 3400-3500 m snm. (FIGURA 2) se registran dos comunidades vegetales claramente diferenciadas, tanto por los especimenes que las constituyen como por su concentración espacial.

La comunidad predominante es la de tipo vega o bofedal constituía por vegetación halófila (Cabrera, 1976), cuyo aspecto es la de un césped corto que crece en torno a los sectores mejor irrigados, tales como las márgenes y planicies de inundación de los ríos y en donde las aguas subterráneas se encuentran próximas a la superficie del terreno. La cobertura vegetal en este sector está altamente concentrada, abarcando entre un 70 y $95 \%$ del suelo.

Las plantas que crecen son pequeñas, generalmente tiernas (pe. juncáceas Juncus sp.-, gramíneas -Festuca sp.-, musgos, etc.). En su mayoría son preferidas por los animales de rebaños en razón de su palatabilidad. Motivo por el cual pastan en esta unidad vegetacional ovinos, caprinos y camélidos.

La comunidad del tolar conformada por especimenes de tipo arbustivo como Acantholippia sp., Senecio sp., Atriplex sp., Neosparton sp., etc., se extiende a continuación de la anterior y se distribuye de forma dispersa, por lo que la cobertura vegetal es escasa; cubriendo en tono a un $20 \%$ del suelo. El potencial de este sector es principalmente forrajero, aunque muchas especies arbustivas son utilizadas por los lugareños como leña para combustible. 
En los sectores intermedios, entre los 3500-3800 m snm., también se encuentran las comunidades de vega y de tolar. De modo semejante a lo observado en el precedente nivel altitudinal, las comunidades de vega tienen una distribución vinculada a la existencia de agua en el medio, pero en este caso se restringe, solamente, a las márgenes de los ríos; donde la cobertura vegetal comprende entre un 90 y $100 \%$ de la superficie. En cambio, la vegetación de tolar al tener una distribución más amplia, abarca tanto las zonas de faldeos, de campos como de pampas y llega a extenderse hasta por encima de los farallones de ignimbritas terrazas estructurales-, cubriendo entre un 25 y un $75 \%$ del suelo. Sobre algunos sectores de campos y de pampas crecen también diversas especies arbustivas, siendo las más abundantemente representadas la rica rica -Fabiana densa-, la añagua -Adesmia horridiuscula- y la lejía -Baccharis incarum-, etc.

En este gradiente topográfico pastan algunos rebaños de ovejas y cabras, a pesar de que su mayor potencial se relaciona con el aprovisionamiento de leña para combustible y con la recolección de hierbas con fines medicinales, usadas como infusión. 


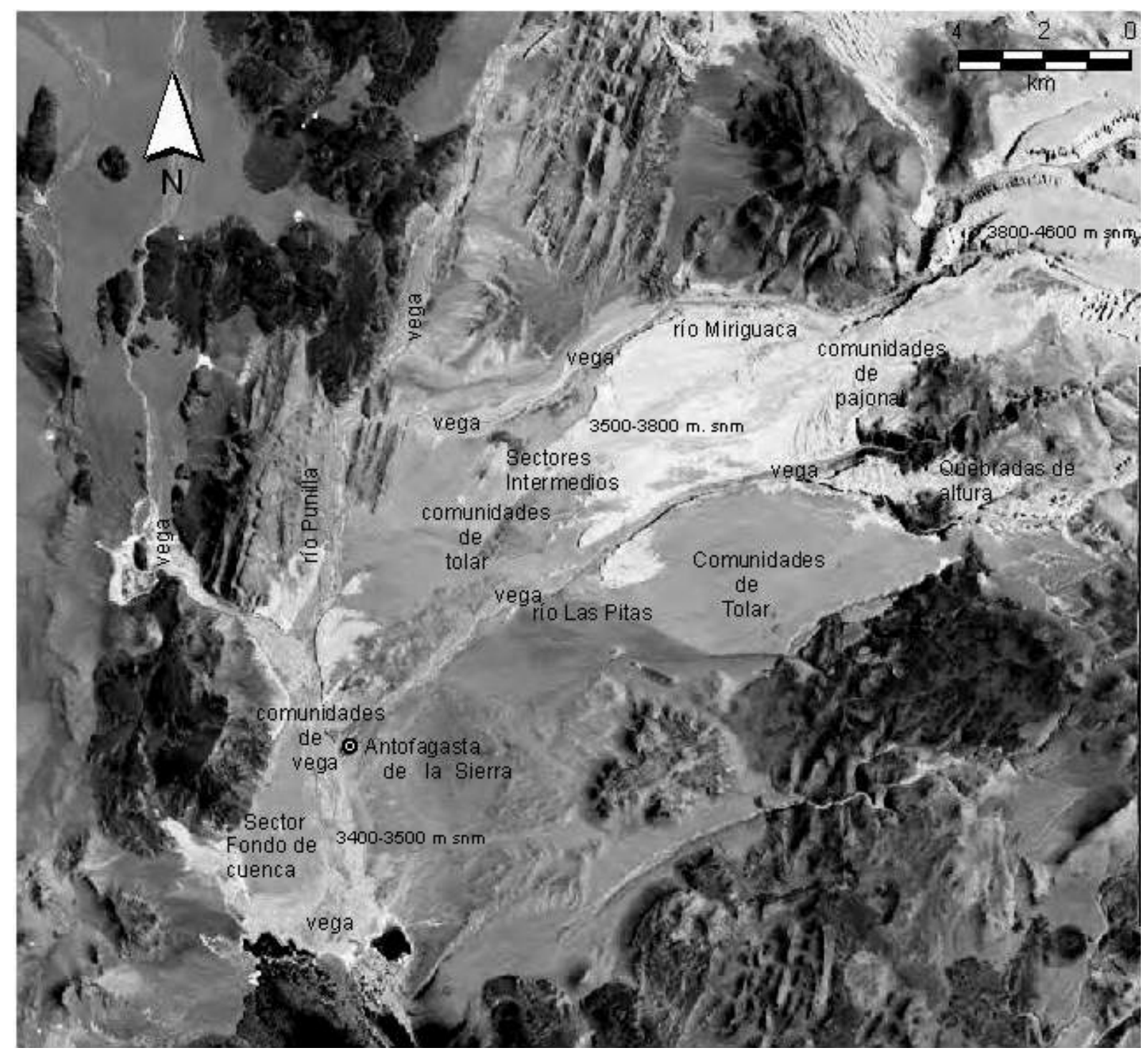

FIGURA 2. Niveles altitudinales y comunidades vegetales

En las quebradas de altura, entre los 3800-4600 m snm., las comunidades vegetales muestran una alta variabilidad debido a las diferencias topográficas que presenta el relieve, vinculadas entre sí por pendientes abruptas y escarpas que caen en ángulo recto.

En este espacio, las comunidades de vega están ubicadas al pie de los farallones rocosos que conforman los faldeos de las quebradas alcanzando una extensión variable. La capa vegetal cubre entre un 80 y $90 \%$ de los suelos; observándose sectores muy erosionados debido a que los rebaños de llamas que allí pastan los utilizan como revolcaderos.

A continuación de la comunidad de vega es posible encontrar especimenes propios de los faldeos de quebradas y de las pampas altas, entre los que están 
representadas especies arbustivas del tipo tolar, que guardan una gran diversidad y que son consumidas por rebaños de llamas, vicuñas y burros.

Por encima de los 4200 m snm. se encuentra la comunidad del pajonal -Stipa sp.-, donde predominan las juncáceas y las gramíneas; presentando una cobertura vegetal que ocupa entre un 25 y $30 \%$ de la superficie del suelo. En este sector se observan pastando tropillas de camélidos, particularmente de vicuñas.

\subsection{Fauna domesticada}

La evaluación de los animales domesticados se refiere a su impacto sobre las pasturas actuales y sus usos reales y posibles (TABLA 4).

A pesar de que la llama es una especie adaptada al ambiente puneño y su etología y manejo son parte de los conocimientos tradicionales de los pobladores, su cría no es tan habitual como podría esperarse. Constituyen solamente el $45 \%$ de los animales que conforman los rebaños.

El motivo por el cual una buena parte de los productores locales eligen propiciar rebaños mixtos de camélidos y ovicápridos podría explicarse en que el objetivo de las unidades domésticas no es la producción inmediata de excedentes, sino el de ser autosuficientes y perpetuarse en el tiempo, por lo que sus decisiones se dirigen a diversificar el riesgo de producir un único tipo de animal de rebaño.

La conformación de rebaños mixtos es una forma de prorratear el riesgo ambiental, propio de los enclaves desérticos, y de hacer frente a los avatares en la demanda de productos y derivados dentro y fuera de la unidad familiar de producción; al obtener una mayor gama de elementos consumibles y de cambio.

\begin{tabular}{|l|l|l|l|}
\cline { 2 - 4 } \multicolumn{1}{c|}{} & Aprovechamiento de pasturas naturales & Usos Actuales & Usos Potenciales \\
\hline Llamas & óptimo & carne, cuero, fibra & mascotas, ecoturismo \\
\hline Cabras & bueno, puede ocasionar estrés & carne, cuero, leche & $\begin{array}{l}\text { productos primarios y } \\
\text { derivados }\end{array}$ \\
\hline Ovejas & bueno, puede ocasionar estrés & $\begin{array}{l}\text { carne, cuero, fibra, } \\
\text { leche }\end{array}$ & $\begin{array}{l}\text { productos primarios y } \\
\text { derivados }\end{array}$ \\
\hline Burros & estrés & eventualmente carga & animales de paseo \\
\hline Mulas & estrés & eventualmente carga & animales de paseo \\
\hline Caballos & bueno & transporte & transporte y paseo \\
\hline
\end{tabular}

TABLA 4. Fauna domesticada: impactos que infligen y usos actuales y potenciales 
Los diferentes requerimientos alimenticios de las distintas especies, en cuanto a sus preferencias de pastos, disminuye el impacto negativo sobre las pasturas, que en vez de presionar sobre una misma comunidad vegetal hace posible el aprovechamiento de la diversidad vegetal existente. A esto cabe agregar que cada especie de rebaño puede ser afectada por enfermedades específicas, que difieren en sus causas y características, a la vez que son vulnerables de maneras diferentes a la rigurosidad climática del entorno (Göbel 1994). Estos argumentos indican que la diversificación en la composición de rebaños amortiguaría el impacto de riesgos climáticos, ecológicos y económicos.

Los rebaños mixtos, también hacen posible optimizar la mano de obra, puesto que los ovicápridos exigen un cuidado muy intenso en la época de cría -entre junio y agosto-, momento en que el control de las llamas es más laxo. Esta situación cambia entre enero y marzo, durante la parición de las llamas cuando las crías son acechadas por predadores, por lo que necesitan de un mayor control (Göbel 1994).

Por otra parte, los pastores conocen perfectamente la capacidad límite de sus tierras para sustentar animales y no permiten que sus rebaños aumenten de manera ilimitada. Prevén que los animales "ganados" un año serán "perdidos" en el otro, dado que no cuentan con formas de hacer frente a la escasez estacional de pasturas. Por lo tanto, si logran tener una diferencia positiva, la decisión será venderlos o trocarlos.

El tamaño de los rebaños, también es tenido en cuenta durante la trashumancia, en cuanto a la factibilidad de poder mover un número determinado de cabezas y en el acceso a las pasturas en las localizaciones hacia donde son trasladados.

La competencia que ejercen burros y mulas con los rebaños mixtos se resume en el alto consumo de pastos. Particularmente si se tiene en cuenta que burros y mulas no presentan ninguna clase de uso desde el momento en que ya no fueron utilizados como animales de carga, a partir del cierre de la Mina La Causalidad y del reemplazo por el transito automotor una vez abierta la ruta nacional 40. En consecuencia, su cría cayó en el más abrupto desinterés y en la pérdida del control en su reproducción. Sin embargo, el ganado caballar, que tiene hábitos de consumo semejantes al asnar y mular, es utilizado también como medio de transporte, algo que salvaguarda el gasto energético que ocasiona. 


\subsection{Fauna silvestre}

La evaluación de la fauna silvestre se refiere a las posibilidades de obtención de productos primarios y secundarios a partir de su explotación (TABLA 5), en relación con las pasturas actuales y las competencias inter-específicas que se genera entre ellas y con la fauna domesticada.

\begin{tabular}{|l|l|l|l|l|}
\cline { 2 - 5 } \multicolumn{1}{c|}{} & $\begin{array}{l}\text { Aprovechamiento } \\
\text { pasturas naturales }\end{array}$ & Usos Actuales & $\begin{array}{l}\text { Estado de } \\
\text { conservación }\end{array}$ & Usos Potenciales \\
\hline Vicuñas & Óptimo & esquila experimental & Vulnerable & fibras, ecoturismo \\
\hline Suri & Óptimo & carne, plumas & Vulnerable & plumas, cuero, carne \\
\hline Flamencos & Ninguno & plumas & Vulnerable & $\begin{array}{l}\text { carne, } \\
\text { ecoturismo }\end{array}$ \\
\hline Liebres & puede ocasionar estrés & ninguno & Bueno & pieles, carne \\
\hline Roedores & & ninguno & Bueno & pieles, carne \\
\hline $\begin{array}{l}\text { Reptiles y yatrios } \\
\text { batracios }\end{array}$ & Ninguno & ninguno & Bueno & mascotas \\
\hline
\end{tabular}

TABLA 5. Fauna silvestre: impactos que infligen y usos actuales y potenciales

Las vicuñas no infligen mayor presión sobre las pasturas naturales debido a la particular conformación de las piezas dentarias y de la estructura de sus miembros con almohadillas plantales queratinizadas, que no dañan la superficie del suelo (Dirección de Flora y Fauna Silvestres, 2000). La competencia en el consumo de pastos con la otra especie de camélidos domesticados, parece ser bajo dado que se trata de una especie básicamente pasteadora, a diferencia de la llama que es tanto ramoneadora como pasteadora. No obstante, los pastores sostienen que compiten, principalmente a partir del aumento que registraron luego de ser protegidas por la Convención CITES (1973).

La escasez estacional de pasturas también las afecta, dado que durante el invierno se registra el mayor número de muertes, siendo a la vez víctimas de la predación pumas y de la caza furtiva. Por todo lo expuesto se entiende que se trata de una población que no parece estar descontrolada.

El suri también consume pastos, principalmente tiernos, desde la yema de crecimiento. Sobre este aspecto se apoyan los productores cuando sostienen que compite con sus rebaños en el acceso a las pasturas. Sin embargo, por el momento su impacto, sobre el medio está lejos de ser negativo. 
Las liebres forman parte de la fauna silvestre, a pesar de tratarse de una especie introducida. En los últimos años parece haberse dado un crecimiento en la población, observándoselas con bastante frecuencia. Su impacto sobre el ambiente como las competencias inter-específicas en las que interviene aún no han sido evaluadas. Lo mismo, sucede con los distintos taxones de roedores. Pero debido a que roedores y lagomorfos son animales muy adaptables a diversas condiciones ambientales resultan pasibles de convertirse en plagas sin un control específico o en ausencia de predadores naturales.

Los reptiles y los batracios no han sido valorados en su accionar sobre el medioambiente, aunque se espera que al ser básicamente insectívoros contribuyan al control en la población de distintas clases de insectos.

\subsection{Producción artesanal}

La producción ganadera genera excedentes de fibra animal y cueros, puesto que los animales de rebaño deben ser necesariamente esquilados con una periodicidad de año por medio o cada dos años a lo sumo, mientras que los cueros se acumulan cada vez que se carnea un animal para consumo. Ambas clases de subproductos no son fácilmente trocables con otras unidades domésticas o vendibles a terceros. En el primer caso debido a que se trata de elementos que ya están presentes en las residencias familiares, mientras que en el otro no se encuentran compradores de vellones o de cueros sin manufacturar.

Las escasa tecnofacturas que se realizan tampoco son ubicables de manera inmediata, ya sea porque en todas las unidades domésticas hay quienes saben tejer en telar o a dos agujas o porque las calidades de las artesanías no condicen con las apreciaciones de compradores foráneos.

Los tejidos hechos en telar, tales como mantas, puyos, pequeñas alfombras, peleros para montar a caballo y cintas para cinturones y boleadoras alcanzan una excelente calidad. A pesar de que en el caso de las mantas y de los puyos pueda ser criticable la mezcla de fibras de llamas con las de oveja, puesto que las tecnofacturas íntegramente realizada en lana de camélido tiene mayor calificación por la fineza que adquiere el hilado. Al parecer, la decisión de mezclar distintos tipos lanas no es una carencia de percepción de las diferentes calidades de fibras sino 
una respuesta a la escasez de fibra de camélidos, debido a que los rebaños muestran un número reducido de ejemplares en comparación con los de cabras y ovejas.

Los tejidos a dos agujas de pullóveres, medias, guantes o bufandas, a causa de que las pautas de elaboración tradicionales, en cuanto a las formas y tamaños, y la necesidad de reducir los descartes que se produciría de la separación de las fibras, mantiene a los artesanos alejados de la posibilidad de convertir a su producción doméstica en una eventual venta de bienes exóticos y/o producidos con tecnologías tradicionales y ambientalmente adecuadas fuera del ámbito local.

Existen algunas iniciativas oficiales pero aún no han encontrado el apoyo empresarial para elevar la calidad de las tecnofacturas regionales; capacitando, subsidiando y alentando a la diversificación del mercado de fibra animal. No obstante, la Dirección de Artesanías de la Provincia de Catamarca ha instaurado, también en el marco de la Feria de la Puna, la elección de ganadores de premios y de menciones para aquellos tejedores que cumplan con ciertos criterios de producción. Entre estos cuentan la separación de los distintos tipos de fibras animales -cerda, lana y pelo- en el hilado, la quita de abrojos adheridos, el lavado previo, la homogenización grosor del hilo y la torsión y la estandarización de talles pe. en el caso de los pullóveres que guarden armonía el ancho y el largo de mangas-.

La pretensión es que los tejidos, particularmente de camélidos, por los altos valores que sustenta en los mercados internacionales, alcancen una inserción comercial a través del incentivo indirecto de la premiación; haciendo que los artesanos se vean estimulados a competir para obtener algún galardón, y así comenzar a imitar ciertas pautas de producción.

La mayor expectativa es que a través de una reacción social, que ubique a los ganadores en un lugar de privilegio que quiera ser emulado por los demás pobladores, se busque repetir los criterios de producción esperados por los organizadores de la feria. Se apuesta a que de esta forma los tejedores reformulen sus prácticas tradicionales en las manufacturas textiles y que comiencen a hilar y a tejer sólo lana. El problema evidente es que se sigue sin ofrecer a los productores otro mercado o alternativa para absorber las pérdidas que les ocasionaría el descarte de la cerda y el pelo. 


\section{Evaluación y comentario final}

El desarrollo sustentable de ambientes y regiones busca la integración de aspectos económicos, sociales y ambientales orientados a equilibrar las necesidades de consumo y mejora en la calidad de vida actual sin poner en riesgo las posibilidades de las generaciones futuras de satisfacer sus propias necesidades. Una propuesta de gestión sustentable debería considerar: a) la diversidad cultural, b) la conservación de la bio-diversidad, c) la capacidad de sustentación del ambiente, d) la escasez relativa de los recursos y e) la mejora de la calidad de la vida (Informe de La Haya 1991).

En vista de los conceptos arriba expresados se entiende que los rebaños de llamas, muestran en el presente una alta variabilidad genética, manifiesta en sus características morfológicas y en las diferentes clases de fibras, y que la estrategia de conformación de rebaños mixtos es acorde con las condiciones medioambientales. Por lo tanto su explotación comercial debería garantizar la perpetuación y la diversidad genética de la especie.

No parece aconsejable intentar modificar las formas tradicionales de pastoreo y la percepción de riesgos económicos. Tampoco se debería contribuir a crear necesidades de consumo que no puedan ser satisfechas sin profundos cambios culturales y sin ejercer presión sobre los recursos naturales, puesto que, de lo contrario las producciones familiares deberían verse obligadas a sobrepasar la capacidad de sustentación de las pasturas con el fin de obtener mayores beneficios; más allá de que se trate de rebaños de fauna autóctona, percibidos como de bajo impacto.

Las acciones oficiales y empresariales puestas en marcha para lograr el desarrollo económico de la Puna muestran una fuerte orientación al mercado de lanas, principalmente de llamas por tratarse de una especie de camélido no protegida, por la excelente calidad de la fibra y los altos valores de mercado. Pero esta propuesta que en el corto o mediano plazo parece muy rentable, desecha de plano las demás potencialidades que sustentan las llamas como especie autóctona y limita las posibilidades de reacción de los pastores ante eventuales cambios de rumbos en la inversión de capitales. 
Por lo tanto, la selección orientada en este único sentido podría llevar a la pérdida de la diversidad genética existente. A la vez que desde una perspectiva económica y de desarrollo local, tampoco resulta aconsejable perder las posibilidades de generar distintos mercados de productos autóctonos.

Los empresarios y los entes oficiales sostienen que la producción de rebaños de camélidos sudamericanos, debe hacerse en las zonas donde éstos son originarios, porque de modo contrario, las comunidades locales quedarían fuera del "negocio" cuando son, precisamente, ellas las depositarias de los conocimientos tradicionales sobre las que se sustentarían las explotaciones económicas. Pero esta apreciación apuesta a la producción de rebaños exclusivamente de llamas, lo cual no es acorde con la percepción del riesgo y la diversificación de la producción que realizan los productores locales.

Una preocupación a tener en cuenta es qué sucederá cuando los productores se adecuen a los parámetros del mercado de la lana, inducidos a través de las distintas ediciones de la Feria de la Puna o de cualquier otro incentivo que surja en el futuro, descartando o minimizando la reproducción de animales manchados y de aquellos que no tuvieran una fibra perfecta pero que sí fueran excelentes ejemplares para otras clases de producción comercial, cuando la explotación textil no resulte rentable y la variabilidad genética de los rebaños de llamas haya sido reducida.

En lo que respecta a los rebaños de cabras y ovejas su incidencia en el ambiente no parece ser tan nociva como se pretende hacer creer. Casi 500 años de pastoreo de ovicápridos no parece haber tenido un impacto negativo ni en el ambiente, ni en las economías domésticas. Los daños observados sobre las pasturas se restringen a casos particulares, donde el manejo de rebaños es inadecuado al estar guiado por la búsqueda de un mayor rendimiento por unidad de terreno.

No obstante, es posible introducir mejoras en los rebaños revalorizando la cría de ovejas de raza criolla, por tratarse de una adaptación particular a enclaves puneños; cuyos especimenes son descendientes de los rebaños introducidos en tiempos de la conquista española y que lograron fijar rasgos fenotípicos característicos que se considera menester preservar.

Las propuestas de comercialización de lana de vicuña, obtenida por medio de encierros comunales, se orienta a obtener una alta rentabilidad y a disminuir la caza 
furtiva. Pero por tratarse de una especie protegida el principal beneficiario de la venta de lana es el estado provincial, circunstancia que no parece condecirse con los ideales de desarrollo del área, puesto que la comunidad local queda fuera de las transacciones y no se observa una inversión clara de los beneficios obtenidos en el afianzamiento infraestructural y social de la Puna.

Los intentos por elevar la calidad de la producción artesanal resultan atractivos, ya que no introducen cambios radicales en los cánones de producción tradicional. Tal vez deberían sumarse a las propuestas en marcha campañas de capacitación dirigidas a la estandarización de tamaños en las tecnofacturas y la creación de mercados, de riesgo o subsidiados, para la colocación de las fibras rechazadas en el proceso textil.

Al mismo tiempo, la participación de productores locales en el sistema de mercado requerirá del replanteo de las formas tradicionales de trabajo. Por un lado será necesario sincronizar los hábitos actuales con los ritmos de inversión de capitales, lo que implicará una ruptura en la percepción de tiempos y horarios, la alteración de las relaciones familiares de reciprocidad y obligaciones dentro de la unidad doméstica de producción y de los objetivos perseguidos por esta, que no deberán ya orientarse a garantizar la autosubsistencia sino a generar excedentes intercambiables por moneda.

Las nuevas relaciones sociales tendrían, entre otras consecuencia, que el productor local se convierta en un trabajador por cuenta propia que no "gozaría de las ventajas" del sistema laboral legal porque, entre otras cosas, ingresar y mantenerse en éste le sería imposible, incluso generando excedentes. Dado los nuevos costos de los que debería hacerse cargo, tales como cargas sociales, impositivas, etc.

A partir de lo expuesto, no debe entenderse que no debería implementarse ninguna clase de propuesta de desarrollo económico, ya que es claro que la Puna cuenta con un alto potencial de recursos naturales y que existe un mercado internacional de bienes de lujo o exóticos que potencia el interés de empresarias por el área, ni que se deba inhibir las posibilidades de los antofagasteños a cambiar sus hábitos, dado que esta es una decisión propia de cada individuo. Lo que se trata de expresar es que cualquier emprendimiento debe ser puntualmente evaluado en 
todos sus aspectos, conociendo los costos y beneficios que tiene implicado, y que estos no son solamente económicos.

La creación de nuevas necesidades de consumo y los cambios en los modos de vida, pueden tener diversos efectos negativos, puesto que se ponen en riesgo los conocimientos tradicionales, se modifican las formas de relación entre poblaciones humanas y el ambiente y la calidad de vida de la comunidad, sin proporcionar elementos básicos para paliar los eventuales daños emergentes.

Por último, debe tenerse en cuenta que la percepción que se tiene de las economías de subsistencia es de pobreza y de necesidad, pero esta percepción debe ser corregida. Las comunidades puneñas son pobres, si se las evalúa con los parámetros del mercado, pero son eficientes en cuanto a los objetivos que persiguen y a las metas que alcanzan, al garantizar la subsistencia de todos sus miembros y permitiendo la continuidad del sistema.

\section{Bibliografía}

Bolsi, Antonio (1968). La región de la Puna argentina. En: Nordeste Revista de la Facultad de Humanidades. Universidad del Nordeste, Resistencia, Chaco.

Cabrera, Antonio (1976). Regiones fitogeográficas argentinas. En: Enciclopedia Argentina de Agricultura y Ganadería II, Buenos Aires.

CITES. 1973. Convención sobre el Comercio Internacional de Especies Amenazadas de Fauna y Flora Silvestre, Washington.

Dirección de Flora y Fauna Silvestres (2000). Secretaria de Desarrollo Sustentable y Política Ambiental de la Nación Argentina. Información On Line.

Dollfus, Oliver (1977). El análisis geográfico. Ediciones Oikos-Tau, Barcelona.

Göbel, Barbara (1994). El manejo del riesgo en la economía pastoril de Susques. En: Zooarqueología de Camélidos 1(1):43-56.

Haber, Alejandro (1991). La Estructuración del Recurso Forrajero y el Pastoreo de Camélidos. En: Actas del XI Congreso Nacional de Arqueología Chilena. Tomo II:139-150, Santiago de Chile.

INDEC (1997). Censo Nacional de Población y Vivienda. Serie Análisis Demográfico No 8 , Buenos Aires. 
Informe de la Haya (1991). Simposio celebrado entre 25-27 de noviembre de patrocinado por el Ministerio de Cooperación para el Desarrollo de Holanda y el PNUD en colaboración con la Secretaría de la CNUMAD.

Mora Carpio, Jorge (2000). Atlas geográfico del área de conservación La Amista Pacífico. PROARCAS/CAPAS, Costa Rica.

Núñez, Lautaro y Santoro, Calógero (1988). Cazadores de la puna seca y salada del área centro-sur Andina (Norte de Chile). Estudios Atacameños 9:11-60.

Plan Estratégico Consensuado (1996). Documentos III. Gobierno de la Provincia de Catamarca, Catamarca.

Riesco, Ricardo (1982). El espacio en la geografía. El espacio en las Ciencias. Problemas Fundamentales del Hombre. Editorial Universitaria, Santiago de Chile. 